\title{
A centralidade das políticas sociais no modelo de desenvolvimento britânico do Novo Trabalhismo
}

\author{
André Simões *
}

\begin{abstract}
Resumo
O presente artigo tem como objetivo analisar a centralidade das políticas sociais na estratégia de desenvolvimento britânica no governo do Novo Trabalhismo. Pretende-se mostrar que a concepção de solidariedade e coesão social que marcaram a formação do Welfare State britânico no Pós-II Guerra Mundial foi substituída por uma visão em que as políticas sociais estariam voltadas para o aumento da competitividade e expansão dos mercados, fato este que redefiniu o sistema de proteção social britânico nos moldes do Welfare to Work. Neste sentido, buscar-se-á mostrar a ausência de conexão entre o discurso centrado na exclusividade do mercado de trabalho como lócus do bem-estar social e as evidências empíricas concretamente verificadas.
\end{abstract}

Palavras-chave: Desenvolvimento; Política social; Mercado de trabalho; Reino Unido; Novo Trabalhismo.

\section{Abstract \\ The centrality of social policy in New Labour's development model}

The aim of this article is to analyze the importance of social policies in the British development strategy during the New Labour government. The intention is to show that the conception of solidarity and social cohesion that marked the formation of the British Welfare State in Post-World War II was replaced by a vision where social policies were aimed at increasing competitiveness and expanding markets. This fact redefined the British social protection system shaped by Welfare to Work programs. The article aims to show the lack of connection between the discourse that focused on the labor market as the exclusivity locus of social welfare and the empirical evidence, which was concretely verified.

Keywords: Development; Social policy; Labour market; United Kingdom; New Labour.

JEL P17, I3, I38.

\section{Introdução}

O governo do Novo Trabalhismo ${ }^{1}$ foi marcado pela introdução de uma série de avanços em relação às políticas sociais estabelecidas ao longo da Era

${ }^{*}$ Trabalho recebido em 19 de novembro de 2012 e aprovado em 8 de fevereiro de 2014. O IBGE (Instituto Brasileiro de Geografia e Estatística) não se responsabiliza pelas opiniões, informações, dados e conceitos contidos neste artigo, que são de exclusiva responsabilidade do autor.

*** Analista Socioeconômico do IBGE, Coordenação de População e Indicadores Sociais, Rio de Janeiro, RJ, Brasil. E-mail: andresimoes36@gmail.com.

(1) O Novo Trabalhismo correspondeu a um período de 14 anos de governo (1997-2010) conduzido pelo Partido Trabalhista Britânico. Ele teve início com o governo do Primeiro Ministro Tony Blair (1997-2007), tendo o mesmo sido sucedido pelo seu até então Chanceler e Ministro das Finanças, Gordon Brown (2007-2010). 
Thatcher ${ }^{2}$, ao mesmo tempo em que manteve praticamente intactos os fundamentos que conceberam tais políticas. É importante ressaltar que esta tensão entre mudanças e continuidades marcou a atuação do governo no campo social e econômico, o que coloca a discussão das políticas sociais durante a gestão dos Primeiros Ministros Tony Blair e Gordon Brown em um campo significativamente complexo de análise.

Cabe destacar, em primeiro lugar, a incorporação de novas ideias ao arcabouço de políticas do governo, fato este que tornou as políticas sociais elementos centrais à estratégia de desenvolvimento do Novo Trabalhismo. Para tanto, o governo do Novo Trabalhismo introduziu uma série de modificações em alguns dos pilares que fundamentavam o conceito do Welfare State, como, por exemplo, a concepção de cidadania e de bem-estar social. Ambos passaram a ter seus significados vinculados a condicionalidades explícitas, como a participação dos indivíduos no mercado de trabalho, fato este que conferiu às políticas sociais uma conotação mais mercantil, subordinando-as, portanto, às políticas econômicas e questionando o campo dos direitos de cidadania, como o direito ao trabalho.

O presente artigo se insere no âmbito desta problemática. Pretende-se analisar como o processo de reestruturação das políticas sociais - especialmente as políticas de transferências de renda - no Reino Unido fez parte da estratégia do governo do Novo Trabalhismo de inserir a dimensão social em uma ordem mercantil, viabilizando, dessa forma, a (re)articulação entre as políticas econômicas e sociais. Refutando os ideais de solidariedade e coesão social que permearam o processo de consolidação do Welfare State no Pós-II Guerra Mundial e que viabilizaram esta articulação a partir do foco na expansão da demanda agregada, as políticas sociais dos governos Tony Blair e Gordon Brown foram redefinidas a partir das mudanças implementadas pela agenda neoliberal, de orientação monetarista, da Primeira Ministra Margareth Thatcher.

O trabalho se encontra dividido em cinco partes, além desta introdução. Em primeiro lugar, apresentam-se as principais mudanças realizadas pelo governo Thatcher no campo econômico e social, onde se procurará mostrar seus principais efeitos sobre as condições de vida da população.

$\mathrm{Na}$ segunda parte, é apresentada a tensão que envolve mudanças e continuidades entre as políticas da Era Thatcher e as do Novo Trabalhismo. Objetivase, com isso, mostrar que este último governo atribuiu uma função mais precisa às políticas sociais na estratégia de desenvolvimento britânica sem, contudo, romper com os pressupostos que fundamentaram as reformas estabelecidas ao longo do governo anterior.

(2) Designou-se por Era Thatcher o período entre 1979 e 1997, o qual compreende, inclusive, o governo do Primeiro Ministro John Major (1990-1997). 
A terceira parte aprofunda o conteúdo desenvolvido na seção anterior ao apresentar as ideias que permitiram incorporar as políticas sociais - principalmente as políticas de transferência de renda - ao modelo de desenvolvimento britânico. Estas ideias foram desenvolvidas no âmbito do que ficou conhecido como a ideologia da Terceira Via, que defendia uma compreensão diferente em relação a uma série de questões relevantes para o desenvolvimento dos países, dentre as quais, o papel do Estado e das políticas sociais. Procurar-se-á mostrar como as ideias da Terceira Via viabilizaram a reformulação das políticas sociais - em especial as de manutenção da renda - de forma que as mesmas passassem a se articular positivamente com as políticas econômicas.

A quarta parte analisa com mais profundidade as relações entre as políticas econômicas e sociais estabelecidas a partir da incorporação das ideias da Terceira Via à estratégia de desenvolvimento do Novo Trabalhismo. O objetivo é mostrar que o mercado de trabalho também viabilizou a articulação entre estas duas políticas no período mais recente devido à semelhança da busca pelo pleno emprego no Pós-II Guerra Mundial. Contrariamente ao primeiro período, entretanto, o estímulo à demanda agregada não foi o foco da atuação do Estado, que passou a estimular a expansão das condições de oferta da economia, implicando, portanto, no desenho de políticas sociais voltadas para garantia de ganhos de eficiência econômica, seja por meio da redução dos custos de produção das empresas ou pelo controle dos gastos governamentais.

Por fim, na quinta parte serão apresentados e discutidos alguns indicadores sociais e de mercado de trabalho para o período 1997-2005, que apresentaram significativa melhoria, quando comparados com a Era Thatcher. Ao se proceder a uma análise mais aprofundada, no entanto, ver-se-á que estes avanços não romperam com a estrutura do mercado de trabalho montada pelo governo anterior, o que justificou a adoção de um novo sistema de benefícios direcionados para as pessoas que se encontravam no mercado de trabalho.

Procurar-se-á, nesta parte, desvendar a relação sinérgica entre flexibilização do emprego em uma sociedade pós-industrial e a ampliação do workfare state no âmbito das políticas de manutenção da renda. Cabe destacar, como elemento catalisador desta sinergia, a mudança na forma de financiamento destas políticas que se deslocaram das transferências monetárias diretas para a concessão de crédito tributário.

\section{A herança da Era Thatcher}

O período que se inicia com a chegada ao poder da Primeira Ministra Margaret Thatcher pode ser tomado como resultado de uma série de acontecimentos ocorridos tanto no plano econômico como político e que criaram as condições 
favoráveis para o avanço do pensamento neoliberal. No plano econômico, destacamse duas crises que, em conjunto, minaram a efetividade das políticas econômicas do período Pós-II Guerra Mundial: cabe destacar os efeitos que as duas Crises do Petróleo (1973 e 1979) tiveram sobre a elevação do preço dessa matéria-prima no mercado internacional, com efeitos expansivos não apenas sobre a inflação doméstica, mas também sobre os custos de produção das empresas. A redução do ritmo de crescimento da produção nos países centrais aumentou as taxas de desemprego, mesmo em um contexto de crescimento da inflação, fenômeno que ficou conhecido como stagflação.

Observa-se, nesse período, uma ineficiência das políticas econômicas do Pós-II Guerra Mundial em combater a crise que se abateu sobre as economias centrais. Nesse sentido, mudanças no campo político ocorreram como uma resposta às transformações no campo econômico, na medida em que as coalizões políticas formadas no Pós-Guerra não estavam conseguindo enfrentar a crise econômica com a utilização dos instrumentos clássicos de política econômica vinculados à tradição keynesiana da síntese neoclássica, abrindo caminho para a ascensão ao poder de coalizões políticas defensoras das políticas econômicas ortodoxas como fundamentais para a estabilização das economias nacionais.

É dentro deste contexto que se podem situar as profundas mudanças implementadas na economia britânica, as quais repercutiram as transformações na natureza das políticas econômicas. Para Hall (1990), os processos que minaram a efetividade das políticas econômicas vinculadas à síntese neoclássica no combate à crise dos anos 70 pavimentaram o caminho para o florescimento das políticas monetaristas, o que, em sua visão, marcou a instituição de um novo paradigma de política econômica ${ }^{3}$. Este novo paradigma não se institucionalizou apenas por meio da introdução de novos instrumentos de política, mas principalmente pelas mudanças nos objetivos a serem almejados pelas referidas políticas. No caso do Reino Unido, a busca pelo pleno emprego, que até então era o grande objetivo da política econômica do Pós-II Guerra Mundial foi deixado de lado, cedendo espaço para as políticas de controle da inflação, meta atingida por meio da manutenção de altas

(3) A abordagem de Hall (1990) parte do pressuposto de que as ideias possuem um papel fundamental na difusão e consolidação das políticas, sendo estas concebidas como um aprendizado (policy learning). Nesse sentido, os formuladores de políticas atuam no âmbito de um conjunto de ideias que especificam não apenas os objetivos das políticas e os seus instrumentos de atuação, como também revelam a natureza dos problemas que propiciaram o seu desenvolvimento. A esta relação entre o contexto específico de desenvolvimento das ideias e a sua difusão por meio das políticas, o autor chama de paradigma de política (policy paradigm). Um novo paradigma de política se impõe na medida em que a natureza dos problemas a serem resolvidos se transforma, eliminando, dessa forma, o antigo paradigma, já que as ideias que alimentam a elaboração de suas políticas não são efetivas na resolução dos novos problemas. Em outras palavras, a difusão das ideias via aprendizado é a grande responsável pelas mudanças de paradigmas, sendo o contexto em que floresceram fundamentais para garantir a consolidação do novo paradigma. 
taxas de desemprego, o que mostra a natureza radical do processo de instituição do novo paradigma.

A introdução do novo paradigma de política econômica forneceu o suporte à estratégia de ajuste e reestruturação da economia britânica. Contrariamente a países como Japão e Alemanha, que optaram por uma reestruturação industrial como alternativa à saída da crise, o Reino Unido implementou uma profunda e extensa desregulamentação do mercado financeiro, seguida por uma série de privatizações de empresas que estavam nas mãos do Estado desde o Pós-II Guerra Mundial (Tavares, 1993). Esta reestruturação econômica promoveu a redução no ritmo de crescimento da atividade industrial, levando ao aumento do desemprego nas indústrias, acompanhado pelo crescimento de empregos de meio período (part time), principalmente nas ocupações vinculadas às atividades de serviços, as quais passaram ditar o padrão de crescimento da economia britânica. Do ponto de vista político, a principal consequência das reformas conservadoras se encontra no enfraquecimento do poder dos sindicatos, que durante todo o período do Pós-II Guerra Mundial tivera forte influência nas negociações salariais, assim como na condução da política econômica. A promulgação de uma série de legislações, ao longo dos anos 80, visava a limitação da atividade sindical, mediante restrição do direito à greve, bem como a supressão dos canais formais de comunicação entre governo e sindicatos, a qual fortaleceu o poder do primeiro nos processos decisórios.

Este processo foi responsável pelas transformações significativas na estrutura da economia e da sociedade britânica ao longo de toda a década de 80 . $\mathrm{O}$ aumento nos diferenciais de rendimento, desigualdade social e dos índices de pobreza - sobretudo da pobreza infantil - foi resultado das tentativas de criação de um sistema econômico desregulamentado e conduzido unicamente pelas forças mercantis (Gráfico 1).

Tal tendência também pode ser observada ao se comparar alguns indicadores econômicos e sociais britânicos com outros países europeus. Ainda que o Reino Unido não tenha verificado uma queda expressiva em seu PIB per capita nos períodos analisados na Tabela 1 - quando comparado aos demais países - seus indicadores sociais se encontravam em patamares inferiores, revelando, com isso, a intensidade do processo de reestruturação econômica.

Neste contexto, as políticas sociais, que até então desempenhavam papel central na estratégia de desenvolvimento britânica, tiveram suas funções redefinidas. Sua subordinação às políticas econômicas monetaristas promoveu mudanças em seu formato, limitando o escopo de atuação a intervenções residuais, como forma de não comprometer o equilíbrio fiscal e orçamentário do país. 


\section{Gráfico 1}

Proporção de alguns indicadores sociais e de gastos e benefícios sociais Reino Unido - 1979 e 1995

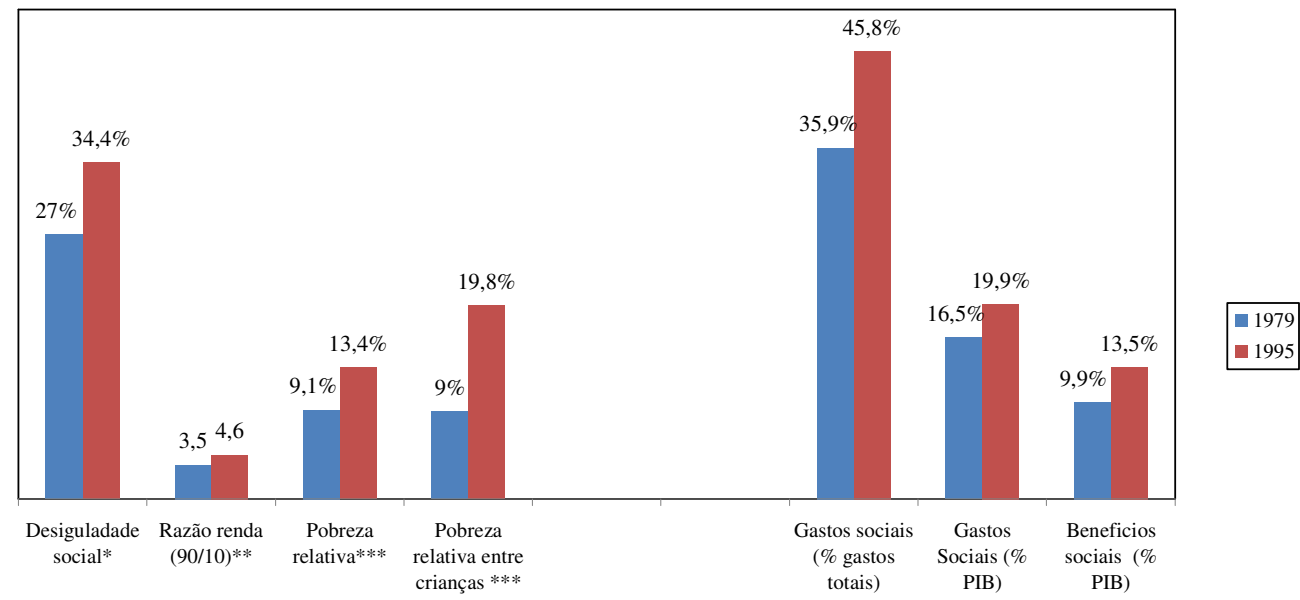

* Índice de Gini (em percentual); ${ }^{* *}$ Razão entre a renda dos $10 \%$ mais ricos e $10 \%$ mais pobres;

${ }^{* * *}$ Percentual da população com renda abaixo de $50 \%$ da renda mediana.

Fonte: Luxembourg Income Study: OECD (stat.extract); Institute of Fiscal Studies (IFS).

Tabela 1

Indicadores sociais e de crescimento do PIB per capita Reino Unido e países europeus selecionados

\begin{tabular}{|c|c|c|c|c|c|}
\hline \multirow[t]{2}{*}{ Países } & \multirow[t]{2}{*}{$\begin{array}{c}\text { Índice de } \\
\text { Gini }\end{array}$} & \multirow{2}{*}{$\begin{array}{c}\text { Razão de Renda } \\
\qquad(90 / 10) \\
(\%)\end{array}$} & \multirow{2}{*}{$\begin{array}{l}\text { Pobreza } \\
\text { relativa* } \\
\qquad \%)\end{array}$} & \multicolumn{2}{|c|}{$\begin{array}{c}\text { Média das Taxas } \\
\text { de Crescimento do PIB per } \\
\text { capita (\%) }\end{array}$} \\
\hline & & & & $1960 / 1970$ & $1980 / 1990$ \\
\hline Alemanha & 0,258 & 3,0 & 5,6 & 5,0 & 2,1 \\
\hline França & 0,287 & 3,5 & 8,9 & 5,7 & 2,3 \\
\hline Reino Unido & 0,336 & 4,7 & 14,6 & 3,0 & 2,2 \\
\hline Suécia & 0,229 & 2,8 & 6,7 & 4,6 & 2,0 \\
\hline Noruega & 0,231 & 2,8 & 6,4 & 4,5 & 2,7 \\
\hline Holanda & 0,266 & 3,0 & 6,3 & 5,4 & 2,1 \\
\hline Dinamarca & 0,238 & 2,9 & 7,2 & 4,7 & 1,7 \\
\hline
\end{tabular}

* Percentual da População com renda abaixo de $50 \%$ da renda mediana

Nota: As informações sobre desigualdade, renda e pobreza se referem ao início dos anos de 1990.

Fonte: Luxemburg Income Study e Estatísticas da OCDE.

De fato as políticas sociais sofreram uma significativa reestruturação, o que implicou em mudanças em sua natureza, cuja principal característica está no enfraquecimento de seu papel em garantir elevados níveis de desmercantilização da 
vida social, por meio da adoção de políticas preventivas. Houve, por outro lado, o fortalecimento de sua função compensatória, o que implicou na adoção de políticas sociais que atuavam apenas quando o mercado apresentava ineficiências, fato este que justificou a adoção de políticas residuais ex post. Em outras palavras, objetivavase impingir uma articulação entre as políticas econômicas e sociais na qual estas últimas estariam completamente submetidas à lógica de funcionamento do sistema econômico, num movimento diferente do observado no Pós-II Guerra Mundial, em que a incorporação dos direitos sociais à cidadania moldou não apenas o formato das políticas sociais, mas colocou-as em posição central na articulação com as políticas econômicas.

A análise das legislações elaboradas pelo governo conservador ajuda a entender a natureza deste processo de reestruturação. Entre 1986 e 1990 foram promulgados os seguintes documentos: o Social Security Act (1986); o Housing Act e o Educational Reform Act (1988); o White Paper Working for Patient (1989); e o National Service and Community Care Act (1990). Propunha-se, nestes documentos, formas de "desregulamentação" das políticas sociais, ou seja, o Estado não seria o único provedor dos serviços sociais, abrindo espaço para a participação do setor privado, que atuaria tanto na provisão dos serviços (na habitação e nos planos de aposentadoria, por exemplo), como na parceria com o Estado (caso do setor de saúde e da assistência social). A ideia do governo era introduzir formas de gestão privada no âmbito da prestação de serviços públicos, o que significava, em outros termos, o aumento da competitividade e, por conseguinte, da eficiência do sistema ${ }^{4}$.

É importante ressaltar que ainda que as políticas sociais tenham sido reestruturadas e adquirido feições mercantis neste período, seu peso no orçamento britânico não sofreu redução, como pode ser notado no crescimento dos gastos e dos benefícios sociais em relação ao PIB no período de 1979 a 2005 (Gráfico 1). Isso se deveu aos efeitos que o avanço do processo de desregulamentação e reestruturação econômica impôs sobre o tecido social britânico, expondo um contingente maior de indivíduos a situações de vulnerabilidade social e aumentando, com isso, a pressão sobre o governo por maiores gastos com os programas sociais.

Esta constatação, no entanto, não impediu que mudanças substanciais fossem verificadas na organização econômica e social britânica. Ao condicionar o comportamento das instituições políticas e sociais à lógica do mercado, o governo Thatcher rompeu os laços de coesão social que caracterizavam a sociedade britânica desde o Pós-II Guerra Mundial, pavimentando um novo caminho de políticas que

(4) Para Le Grand (1991) estas reformas objetivaram a introdução de mecanismos de quase-mercado (quasimarket) na provisão dos serviços públicos - especialmente na saúde -, o que significava que o Estado não seria mais o financiador e o provedor das políticas sociais, ficando principalmente com a primeira das funções. A provisão dos serviços públicos ficaria a cargo de fundações e entidades privadas que competiriam entre si pelos recursos disponibilizados pelo Estado. 
passou a ser trilhado pelos governantes. As próximas seções analisam este fenômeno à luz do governo do Novo Trabalhismo.

\section{Novo Trabalhismo e a Era Thatcher: semelhanças e diferenças}

A vitória dos trabalhistas em 1997 não marcou uma ruptura em relação à Era Thatcher nem, muito menos, significou o retorno às políticas do Pós-II Guerra Mundial. Pelo contrário, a reformulação dos ideais do partido, ao longo de toda a década de 90, permitiu a emergência de segmentos com forte articulação com a classe média e a elite britânica, enfraquecendo ainda mais a influência dos sindicatos e da classe trabalhadora, os quais tiveram sua atuação restringida ao longo de todo o governo conservador. De acordo com Faucher-King e Le Galès (2010), as sucessivas derrotas impingidas aos trabalhistas, ao longo de toda a década de 80 e no início dos anos 90, juntamente com o fracasso das políticas de combate à crise econômica dos anos 70 , foram as principais responsáveis pelo fortalecimento dos segmentos que defendiam a reformulação da agenda política, o que culminou com ascensão ao poder de uma coalizão política que passou a ser chamada de Novo Trabalhismo, cujas figuras centrais são o Primeiro Ministro Tony Blair e o seu Chanceler e Ministro das Finanças, Gordon Brown.

Embora tenham sido eleitos com um discurso de oposição às políticas implementadas pelos conservadores, em especial pelos seus efeitos sobre as condições de vida da população, que se deterioraram ao longo do tempo, o Novo Trabalhismo não representou uma ruptura em relação às políticas anteriores, optando, por outro lado, pela sua reformulação por meio da agregação de novas ideias (Holden, 2003). Em outras palavras, aspectos centrais das políticas da Era Thatcher, como apoio à globalização e reestruturação econômica, flexibilização do mercado de trabalho, competitividade e equilíbrio macroeconômico foram mantidos, ocupando o espaço antes pertencente às políticas de administração da demanda agregada, negociação salarial entre patrões e empregados e crescimento baseado no incremento da produção industrial, que prevaleceram no período Pós-II Guerra Mundial e fizeram parte, até início dos anos 1990, da agenda trabalhista.

Dentro desta linha de análise, autores como Jessop (2003), Faucher-King e Le Galès (2010), Holden (2003), Lund (2008), dentre outros, desenvolveram trabalhos nos quais defendem que as ideias que subsidiaram a construção da agenda de políticas do Novo Trabalhismo mantiveram-se no campo neoclássico, já que as mesmas não promoveram rupturas com os processos iniciados com as reformas conservadoras nos anos 80 . Isso significa dizer que as políticas sociais neste período foram concebidas dentro de uma lógica voltada para a expansão das relações mercantis, na qual fatores como flexibilidade, mobilidade e competitividade tornaram-se ainda mais relevantes, sendo, portanto, elementos fundamentais à estratégia de desenvolvimento implementada pelo Novo Trabalhismo. 
Faucher-King e Le Galès (2010), por exemplo, procuram mostrar que a fundamentação das políticas implementadas pelo Primeiro Ministro Tony Blair possui suas raízes nas reformas do governo Thatcher, cujos impactos foram profundos na forma de funcionamento da administração pública. Nesse sentido, a modernização dos instrumentos de gestão pública, como a introdução de procedimentos baseados em relações de quase-mercado, criação de indicadores de avaliação da eficiência dos serviços prestados, gestão por resultados, bem como o incentivo para o aumento da provisão privada dos serviços públicos foram mantidos, ganhando, inclusive, maior densidade. Nas palavras dos autores: "The bureaucratic revolution initiated by Margareth Thatcher was at the heart of Tony's Blair strategy for modernizing Britain. Her legacy was invoked, taken over, and (of course) modernized" (Faucher-King; Le Galès, 2010, p. 43).

É importante ressaltar, no entanto, que a despeito de o Novo Trabalhismo ter aprofundado as reformas nas políticas sociais iniciadas na Era Thatcher, as mesmas ganharam um significado diferente, ou seja, aos pressupostos que fundamentaram a formulação das políticas sociais no período conservador foram agregadas novas ideias, cujo principal efeito se encontrava em realçar sua importância na estratégia de desenvolvimento do país. Embora tivessem mantido sua centralidade ao longo de todo o governo conservador, as políticas sociais eram encaradas como um custo, ocupando lugar periférico no processo de reprodução do capitalismo. As reformas neste período visaram o fortalecimento e a autonomia do sistema econômico em relação à influencia das instituições estatais, ficando as políticas sociais sem um papel definido na estratégia de desenvolvimento do país. Como colocado anteriormente, o aumento nos níveis de desigualdade social e pobreza ${ }^{5}$, evidenciaram os limites de uma economia de mercado, "forçando" os governos Thatcher e Major a manterem os gastos sociais em elevados patamares, estando estes, entretanto, vinculados não apenas à proteção da população, mas também às reformas que introduziram mudanças na gestão das políticas sociais.

A proposta do Novo Trabalhismo foi, dessa forma, atribuir às políticas sociais um papel mais definido no modelo de desenvolvimento do país, fato este que ficou evidente nas constantes críticas feitas aos conservadores durante o período eleitoral, em virtude do aumento dos índices de desigualdade social e pobreza no Reino Unido - especialmente a pobreza infantil. Estas críticas, no entanto, não tinham como objetivo defender um modelo de políticas sociais nos moldes evidenciados no período Pós-II Guerra Mundial, isto é, onde os direitos sociais fundamentavam uma concepção de cidadania que pressupunha o acesso universal a benefícios sociais e aos serviços desmercantilizados. De forma diferente, as políticas sociais do Novo Trabalhismo estavam embasadas por uma visão de que os direitos

(5) De acordo com informações fornecidas pela OCDE, a pobreza infantil subiu de $9 \%$ para $20 \%$ entre 1979 e 1995 no Reino Unido 
sociais deveriam ser conquistados unicamente por meio da participação dos indivíduos no mercado de trabalho, o que traduz uma concepção de cidadania que, nas palavras de Plant (2003, p. 155) "[...] is something that is developed by contributing to the life of society - it is an achievement rather than a status".

Em suma, a proposta do Novo Trabalhismo era reformular o Welfare State no Reino Unido, de forma que o mesmo pudesse atuar numa sociedade cada vez mais globalizada, o que implicava no desenho das políticas sociais condizentes com os critérios de flexibilidade, competitividade e eficiência, fato este que justificava a manutenção dos fundamentos que promoveram as reformas no sistema de proteção social durante a Era Thatcher. A adequação dessas políticas a um novo modelo de desenvolvimento, em que as mesmas recuperassem - principalmente no campo analítico - sua centralidade no capitalismo, só pôde ser concebida pela agregação de novas ideias, que passaram a condicionar o desenvolvimento tanto das políticas econômicas como das sociais. Essas ideias estão na origem da chamada "Terceira Via" (Third Way) e baseiam-se no fato de que o desenvolvimento da economia e sociedade britânica deve ocorrer fundamentalmente por meio da difusão do conhecimento (knowledge-based society) - o qual propiciaria o incremento das inovações tecnológicas e, portanto, da produtividade e da produção - e da inclusão social por meio da participação ativa dos indivíduos no mercado de trabalho. A próxima seção discute com mais profundidade esta questão.

\section{As novas ideias do Novo Trabalhismo e suas relações com as políticas econômicas e sociais}

O Novo Trabalhismo introduziu profundas modificações na forma de conceber as políticas econômicas e sociais, o que fez parte de uma estratégia de promover uma rearticulação entre as mesmas. Ao contrário do que foi feito durante a Era Thatcher, a agenda de políticas propostas pelo Novo Trabalhismo atribuía ao Estado um papel fundamental, além de positivo, no processo de desenvolvimento do país, ou seja, sua função não ficaria restrita a garantir a manutenção das reformas estruturais iniciadas no governo anterior, mas iria além, por meio da criação de oportunidades, para que toda a população tivesse acesso aos benefícios gerados pela globalização.

Essas modificações refletiam uma concepção ideológica que defendia um papel ativo do Estado na promoção do desenvolvimento do Reino Unido, sem que isso significasse sua volta ao protecionismo - ou paternalismo, segundo Giddens (1999) -, prevalecente nos anos posteriores à II Guerra Mundial. Da mesma forma, o Estado não desempenharia apenas a função de conduzir o processo de globalização, fortalecendo os mercados e promovendo a remercantilização da vida social. $O$ Estado, para o Novo Trabalhismo, estaria envolvido em uma nova estratégia de desenvolvimento, que surge como uma alternativa às estratégias acima pontuadas, 
ou seja, mantém o mercado como instituição primaz do capitalismo, mas procura reinseri-lo na estrutura política e social do sistema (Jessop, 2003), como forma de permitir que os frutos de uma economia de mercado fossem direcionados para toda a população. A subseção abaixo apresenta as principais características da Terceira Via, procurando, posteriormente, relacioná-las com as mudanças impingidas no campo econômico.

\subsection{Principais características da terceira via e seus efeitos sobre as relações entre política econômica e política social}

As ideias contidas na Terceira Via objetivavam fornecer elementos que permitissem a criação de elos que articulassem as políticas desenvolvidas no campo econômico com as políticas sociais, como forma de garantir a participação de toda a população no processo de desenvolvimento econômico. Para tanto, defendia a mobilização ativa de todas as instituições econômicas e sociais - como o mercado, o Estado, comunidades e instituições voluntárias - como forma de garantir a inclusão de todos os indivíduos no processo de produção capitalista, o que na visão de Antony Giddens (1999), seu principal teórico, era condição fundamental para a obtenção da igualdade social. De acordo com o referido autor, a Terceira Via pode ser caracterizada a partir de três pilares que, juntos, forneceriam as bases explicativas para as mudanças nos princípios que regem a sociedade britânica: o pilar da governança, o da promoção do bem-estar social e o da cidadania.

$\mathrm{O}$ pilar da governança se refere às formas de articulação entre Estado e mercado e seus efeitos sobre a criação de oportunidades para que os indivíduos possam desenvolver ao máximo suas capacidades individuais, de forma a torná-los independentes das redes assistenciais do Estado. Dessa forma, Giddens (1999) defende que a dicotomia entre Estado e mercado deveria ser substituída por uma sinergia entre ambos, onde o dinamismo do mercado seria canalizado para a obtenção do interesse público. Em outras palavras, a globalização teria uma conotação positiva, caso seus frutos fossem canalizados para o bem-estar da sociedade, o que seria alcançado através da regulação - não coerção - do mercado pelo Estado, ou seja, a ideia de mercado autorregulável é criticada, dando espaço a uma visão do mercado como lócus de criação de oportunidades, o que seria feito em parceria com o Estado.

O segundo pilar se refere à promoção do bem-estar social, que deveria ser garantido exclusivamente por meio da participação de todos os indivíduos - aptos no mercado de trabalho. Neste sentido, Giddens (1999) defende a criação de um "Welfare Positivo", ou seja, um sistema de proteção social que, ao invés de apenas proteger os indivíduos contra a ineficiência de uma economia de mercado, contribua para que os mesmos se tornem mais independentes e aptos a lidarem com as transformações no mundo do trabalho. Com isso, a criação de oportunidades estaria 
no cerne das políticas de bem-estar social defendidas pela Terceira Via, o que significa uma rejeição às políticas que mantêm os indivíduos dependentes de benefícios concedidos pelo Estado. Para tanto, as políticas de Welfare deveriam focar constantemente no investimento em capital humano, seja na política educacional e de capacitação, seja nas políticas voltadas para a manutenção da renda. Nas palavras de Giddens (1999):

A diretriz é o investimento em capital humano sempre que possível, em vez de fornecimento direto de sustento econômico. No lugar do welfare state deveríamos considerar o Estado do Investimento Social, operando no contexto de uma sociedade de welfare positivo (p. 128).

Por fim, o terceiro pilar diz respeito às transformações na concepção de cidadania, a qual passou a estar relacionada a obrigações e condicionalidades, ou seja, os direitos sociais seriam garantidos para aqueles indivíduos que estivessem no mercado de trabalho ou procurando emprego - exceção feita às pessoas incapazes de trabalhar. Em outros termos, a concepção de direitos sociais que estava relacionada à simples condição de pertencimento a uma dada comunidade política (cidadania pelo status) foi substituída por uma cidadania baseada no mérito daqueles indivíduos que estivessem contribuindo para o desenvolvimento da nação. Esta mesma concepção de cidadania pauta o entendimento que os teóricos da Terceira Via têm em relação à desigualdade, cuja redução dependeria da inclusão, no mercado de trabalho, dos grupos populacionais de maior vulnerabilidade (Glyn; Wood, 2001). As questões estruturais referentes à reprodução das desigualdades sociais são deixadas em segundo plano, afastando, da mesma forma, os mecanismos nãomercantis utilizados para sua redução.

A Terceira Via redefiniu um conjunto de ideias que, historicamente, estruturou a organização da sociedade britânica, fornecendo as bases para a continuidade do processo de reestruturação das políticas sociais. Ao condicionarem a obtenção da cidadania à participação de todos os indivíduos no mercado de trabalho, o governo do Novo Trabalhismo propôs uma série de políticas de transferência de renda que beneficiariam mais quem estivesse trabalhando ou procurando emprego em detrimento daqueles que, por algum motivo, estivessem fora do mercado de trabalho.

É importante ressaltar que a operacionalização das ideias contidas na Terceira Via, em especial no campo social, demandava mudanças no campo econômico, em especial nas formas de se conceber o crescimento. Este fator era essencial, pois o aumento na oferta de trabalho era o que permitia a expansão das oportunidades para os indivíduos, garantindo, portanto, o acesso à cidadania e à inclusão social. Refutando tanto as políticas keynesianas, nas quais o crescimento econômico era atribuído ao crescimento da demanda agregada, assim como boa parte da economia neoclássica - em especial a corrente neoliberal - que, embora 
elaborassem suas políticas objetivando a expansão da oferta, não levavam em consideração os impactos das políticas econômicas sobre a expansão do produto, os teóricos da Terceira Via incorporaram ao seu arcabouço de políticas as Novas Teorias do Crescimento (New Growth Theories) ${ }^{6}$.

As novas teorias do crescimento econômico promoveram avanços em relação às teorias do crescimento anteriores ${ }^{7}$ - em que as variações no produto eram determinadas exogenamente - ao tornarem as inovações tecnológicas e as taxas de crescimento populacionais endógenas ao modelo ${ }^{8}$. Em outras palavras, as variações nas quantidades de capital e trabalho teriam impactos positivos sobre o crescimento do produto no longo prazo, já que estimulariam as inovações tecnológicas, aumentando, por sua vez, a produtividade do trabalho. Dessa forma, os retornos de escala passariam a ser crescentes, ao invés de constantes, como nas teorias tradicionais, já que o impacto das inovações tecnológicas sobre a produção seria proporcionalmente superior ao investimento realizado (Aghion; Durlauf, 2007).

É igualmente importante destacar o papel central desempenhado pelas novas ideias na difusão das inovações tecnológicas, o que tornava fundamental o investimento em capital humano. $\mathrm{Na}$ visão dos adeptos das novas teorias do crescimento, o conhecimento - via aprendizado e desenvolvimento de novas ideias - seria o condutor do crescimento econômico, pois através dele é que se viabilizariam as inovações tecnológicas. Nesse sentido, o conhecimento passou a ser o insumo primordial no processo de crescimento econômico dos países o que, para os adeptos desta corrente, justificaria os investimentos na qualificação dos trabalhadores, assim como nos setores de Pesquisa e Desenvolvimento.

As Novas Teorias do Crescimento Econômico forneceram as bases sobre as quais as ideias da Terceira Via prosperaram ao longo de toda a década de 1990, não apenas no Reino Unido, mas em países como os Estados Unidos, França e Itália, e mesmo no Brasil, na medida em que concedia legitimidade às reformas estruturais requeridas pelo processo de globalização, sem, no entanto, abrir mão de um discurso com foco na redução das desigualdades. Isto se tornou possível, pois as referidas teorias não prescindiram da centralidade do Estado, que não restringiu seu papel à promoção das condições para o avanço da internacionalização das economias,

(6) As principais referências sobre as Novas Teorias do Crescimento Econômico são os trabalhos de Robert Lucas (1988); Paul Romer (1986 e Douglass North (1990).

(7) Neste campo, destaca-se a teoria de crescimento formulada, em trabalhos independentes, por Robert Solow (1956) e por Trevor Swan (1956), que ficou conhecido como o modelo Solow-Swan.

(8) Essa foi uma forma de garantir poder explicativo às teorias do crescimento pelo campo neoclássico que, até então, consideravam exógenos os fatores determinantes do crescimento. Até o seu surgimento nos anos de 1980, as teorias que explicavam o crescimento econômico a partir da difusão das inovações tecnológicas se restringiam basicamente à corrente neoschumpteriana (Ver, nesse sentido, Nelson; Sampat, 2001). 
criando, também, incentivos às inovações tecnológicas, por meio do investimento em capital humano, condição necessária para o desenvolvimento de novas ideias.

O Estado, dessa forma, era tido como uma instituição empreendedora, ou seja, seu objetivo estava na expansão das condições de oferta de capital e de trabalho, ambas a partir do investimento em capital humano. $\mathrm{O}$ investimento no desenvolvimento de novas ideias, no primeiro caso, criaria as condições para o avanço das inovações tecnológicas, o que levaria ao aumento da produtividade do trabalhador, garantindo, com isso, a expansão da capacidade produtiva ao longo do tempo. Da mesma forma, o Estado estimularia a oferta de trabalho, por meio de políticas de qualificação e (re)inserção dos indivíduos no mercado de trabalho, condição necessária não apenas para garantir que a demanda por trabalho pelas empresas acompanhe a expansão da sua oferta - promovida pelas inovações tecnológicas -, mas também para que os indivíduos tenham acesso à cidadania e aos direitos sociais a ela vinculados, fato este que evidenciaria o papel mercantil concedido às políticas sociais pela Terceira Via, principalmente às políticas de manutenção da renda.

Em suma, o advento das ideias contidas na ideologia da Terceira Via, assim como as Novas Teorias do Crescimento Econômico, criaram um novo cenário no qual as políticas econômicas e sociais passaram a se relacionar de forma positiva marcando, no caso do Reino Unido, uma diferenciação em relação ao governo conservador. É importante ressaltar, no entanto, que este "novo ambiente" para o desenvolvimento de políticas mesclou-se - e não rompeu - ao paradigma de políticas (econômica e social) que prevaleceu durante a Era Thatcher. Isto porque não foram abandonados os pressupostos básicos de política econômica, que incluíam a disciplina orçamentária e o controle da inflação, nem a lógica que esteve por detrás das reformas das políticas sociais, voltadas para a expansão das relações de mercado, tanto na provisão quanto no seu financiamento. Da mesma forma, não houve o deslocamento do campo analítico no qual estas novas ideias floresceram, ou seja, as mesmas se desenvolveram no campo neoclássico.

Em outras palavras, as políticas sociais e econômicas que prevaleceram na Era Thatcher foram reelaboradas a partir de um novo e bem estruturado arcabouço institucional e conceitual, o que permitiu a rearticulação entre ambas. Pode-se dizer que a introdução dessas novas ideias tornou possível o realinhamento e a definição do papel social do Estado no modelo de desenvolvimento britânico. A próxima seção discute as formas como essas ideias foram operacionalizadas no âmbito das políticas adotadas pelo Novo Trabalhismo.

\section{As políticas sociais no Novo Trabalhismo}

É no âmbito das políticas voltadas para a reestruturação do sistema econômico que o Novo Trabalhismo reformulou a centralidade do Welfare State 
britânico, cuja função principal seria garantir oportunidades para que o maior número de indivíduos pudesse fazer parte do mercado de trabalho. Esta era a condição necessária, dentro da ideologia da Terceira Via, para que os mesmos tivessem acesso aos direitos sociais. O Estado, dessa forma, garantiria não apenas o bem-estar dos cidadãos, mas também a expansão - quantitativa e qualitativa - da oferta de trabalho da economia, garantindo, com isso, o capital humano e a força de trabalho necessária para a expansão da produção. Como, para o Novo Trabalhismo, o bem-estar social está relacionado exclusivamente à participação no mercado de trabalho, o Welfare State passou a ter um significado de Welfare to Work, o que colocou as políticas de manutenção da renda no centro da estratégia de desenvolvimento do Reino Unido. Esta visão da centralidade do trabalho no modelo britânico fica clara na seguinte passagem, extraída do documento oficial intitulado A New Contract to Welfare: the Gateway to Work:

Our priority is to forge an entirely new culture which puts work first and is based on a modern, integrated, flexible service for all. This means a fundamental shift in the way we support our clients - away from merely asking "What money can we pay you?" to "How can we help you become more independent?" In future, we will focus on enabling people to access the wide range of opportunities and support available. We will treat people as individuals, rather than categorise them as 'unemployed', 'lone parent' or 'disabled' - labels that tend to stick permanently and do nothing to help individuals focus on how they can become independent through work (Department of Education and Employment, 1998, p. 3; Grifo nosso).

Neste sentido, o governo promoveu uma série de modificações nas características dos benefícios vinculados à manutenção da renda da população, como forma de criar incentivos para aumentar a participação da população no mercado de trabalho. Comandada pelo Ministro das Finanças e Chanceler Gordon Brown, a mais importante destas modificações esteve na unificação do sistema tributário com o sistema de benefícios, criando um sistema que beneficiava, sobremaneira, mediante incentivos, aquelas pessoas que estivessem trabalhando ou procurando emprego. Procurava-se, com isso, reduzir as armadilhas do desemprego e da pobreza (unemployment and poverty traps), que mantinham os indivíduos fora do mercado de trabalho, já que não precisariam pagar as taxas e os impostos que incidiam sobre quem trabalha. Este novo sistema concedia benefícios proporcionais à renda anual recebida pelos trabalhadores ao longo do ano, na forma de créditos tributários $^{9}$, o que era um incentivo para que os indivíduos se mantivessem no mercado de trabalho,

(9) Os valores dos créditos tributários variam em relação à renda anual do trabalhador. Até uma determinada renda, o trabalhador recebe a totalidade do benefício. A partir de um determinado valor, esse benefício é reduzido progressivamente até cessar. Embora se assemelhe a um sistema de deduções tributárias, a tax credit não paga valores proporcionais ao imposto pago pelo trabalhador. Esse valor é definido de acordo com faixas de renda. 
ou procurando emprego, já que a concessão da maior parte dos benefícios estava condicionada a estes dois fatores ${ }^{10}$.

Embora representassem uma inovação no sistema de proteção social britânico, os créditos tributários têm origem nas reformas introduzidas inicialmente pelo governo Ronald Reagan (1981-1989) nos Estados Unidos e ampliadas posteriormente na gestão do presidente Bill Clinton (1993-2001). Este último buscou criar novos mecanismos - além de expandir os já existentes - que incentivassem, mediante concessão de incentivos, a população pobre a se inserir no mercado de trabalho. O principal destes programas, intitulado Earned Income Tax Credits, é semelhante ao sistema de créditos tributários Britânico, pois concede benefícios apenas aos indivíduos que se encontram no mercado de trabalho, mas que não auferem renda suficiente (Blank, 2002).

Essas reformas no sistema de benefícios foram instituídas em conjunto com uma série de políticas voltadas para a dinamização do mercado de trabalho, o que reforçou ainda mais os vínculos entre as políticas econômicas e sociais de novo formato. $\mathrm{O}$ objetivo era criar condições para elevar o percentual da população economicamente ativa no Reino Unido, evitando, com isso, que o aumento na demanda por trabalho, originada da expansão da economia, pressionasse a elevação da inflação (Glyn; Wood, 2001). Chamadas de New Deal, já que foram concebidas a partir da lógica do Welfare Positivo, essas medidas pretendiam, inicialmente, reduzir as taxas de desemprego dos jovens (18 a 24 anos) e as taxas de desemprego de longo prazo que, na visão dos governantes, eram as duas categorias que mais comprometiam a expansão da oferta de trabalho.

Para tanto, contavam com uma série de mecanismos de incentivo e coerção que estimulavam a procura por trabalho. Em primeiro lugar, aqueles que estavam no mercado de trabalho "eram premiados" com mais benefícios do que quem estava fora dele. Em segundo lugar, o auxílio desemprego seria concedido desde que os trabalhadores desempregados participassem de programas de requalificação, ao mesmo tempo em que se mantivessem procurando trabalho. No caso dos jovens desempregados, especificamente, foram introduzidas quatro opções: trabalho subsidiado, ou seja, o governo daria incentivos a empresas para contratar trabalhadores jovens desempregados; apenas treinamento e qualificação; trabalho voltado para o meio ambiente; e trabalho voluntário (Fraser, 2009). Para Blair e Brown, não haveria uma quinta opção - "there is no fifth option" -, ou seja, a

(10) De acordo com Barr (2004) o papel dos créditos tributários - mais especificamente as working tax credits - era, ao mesmo tempo, combater a pobreza e aumentar a participação da força de trabalho britânica. Em linhas gerais, o sistema concedia benefícios com base em faixas de rendimento, mas condicionava a concessão dos mesmos a um número mínimo de horas de trabalho (Barr, 2004). 
manutenção dos benefícios para jovens aptos a trabalhar, estaria condicionada a sua participação em um dos quatro programas acima listados (Glennester, 2007).

Posteriormente foram implementados programas para absorção de outros estratos populacionais pelo mercado de trabalho, como pais solteiros (lone parents); pessoas "incapazes"; idosos, principalmente aqueles que acabaram de se aposentar, por falta de trabalho; além daqueles que não estavam procurando emprego. A ideia era, ao mesmo tempo, expandir a oferta de trabalho e criar oportunidades para que os indivíduos se tornassem independentes dos benefícios sociais tradicionais, recebendo, por outro lado, incentivos para que permanecessem trabalhando ou procurando emprego. Esta dinâmica evidenciava a centralidade que o novo Welfare State havia adquirido no âmbito do governo do Novo Trabalhismo, sendo importantes, para isso, mudanças na sua concepção, permitindo que se estreitassem os laços entre as políticas econômicas e sociais. Nas palavras de Glyn e Wood (2001):

$<\ldots>$ this approach can be extended from the long term unemployed to other groups who are not working. Lone parents with small children, people claiming disability benefits, those in early retirement because of lack of work, and partners of unemployed people caught in the benefit system's unemployment trap' may all be target for persuasion, by an appropriate mixture of incentives and sanctions, to reenter the labour force. The downward pressure on wages which these additional recruits to the reserve army would bring would allow faster growth. Sustainable employment would rise and non-employment would fall (Glyn; Wood, 2001, p. 53, grifos nossos).

Em suma, a restrição da operacionalização do conceito de bem-estar social como acesso a oportunidades oferecidas pelo mercado de trabalho, produziu transformações no significado do Welfare State britânico, o qual passou a estar vinculado à promoção da autonomia dos indivíduos. Dessa forma, o mercado de trabalho passou a viabilizar a articulação positiva entre a esfera econômica e a esfera social, onde questões como redução da pobreza, desigualdade social e acesso aos direitos sociais passaram a caminhar em conjunto com as questões relacionadas à expansão da atividade econômica. Em outras palavras, o incentivo para que mais indivíduos participassem do mercado de trabalho não tinha como meta apenas a garantia de acesso aos direitos sociais, mas principalmente o crescimento da oferta de trabalho da economia, o que era necessário para que a redução dos custos de produção - via redução dos salários - estimulasse o crescimento do produto.

Dessa forma, o Welfare State britânico perdeu a essência que marcou sua institucionalização no período Pós-II Guerra Mundial, em que aspectos como solidariedade interclasses e críticas à visão de mundo centrada no indivíduo se sobrepôs a questões referentes à eficiência do sistema. A redefinição do papel do Estado ao longo da Era Thatcher criou as bases para que, no governo do Novo 
Trabalhismo, as políticas sociais fossem instrumentalizadas, se tornando funcionais ao processo de expansão dos mercados. Deixando de intervir e modificar o direcionamento das forças de mercado, garantindo mínimos sociais à população independente de sua atuação na esfera mercantil, o Estado britânico passou a condicionar o bem-estar social à participação dos indivíduos no processo de expansão dos mercados.

Conforme analisado na próxima seção, a conjuntura internacional favorável viabilizou o modelo de desenvolvimento do Novo Trabalhismo até meados dos anos 2000, quando a combinação entre crescimento econômico e expansão do mercado de trabalho produziu melhorias nos indicadores sociais. Uma discussão mais detalhada das características do mercado de trabalho britânico, no entanto, problematiza os avanços atribuídos às políticas de Welfare Positivo ao mostrar os limites do mercado laboral como lócus da obtenção do bem-estar social.

\section{A "efetividade" do modelo de desenvolvimento britânico no período 1997- 2005}

O Gráfico 2 mostra que os gastos sociais, como proporção do PIB, tiveram um crescimento pouco expressivo ao longo do período analisado. Tal comportamento se deve basicamente às novas características das políticas de manutenção de renda, que passaram a condicionar o acesso aos benefícios monetários mediante participação compulsória no mercado de trabalho ${ }^{11}$.

Este processo teve como objetivo reduzir a responsabilidade do governo na manutenção dos estratos populacionais tradicionalmente vulneráveis às oscilações do mercado de trabalho. Este custo passa a ser dividido com o setor privado e com a classe trabalhadora. Primeiramente, condicionando esta última ao exercício de alguma atividade remunerada, mesmo que seja precária, para requerimento de qualquer benefício assistencial (workfare). Assim, os demandantes do welfare state passam a ter de comprovar um número de horas semanais trabalhadas.

(11) O National Insurance Act de 1946 e o National Assistance Act de 1948 estabeleceram as bases de expansão das políticas de manutenção da renda no Reino Unido, que se dividia entre a concessão de benefícios contributivos no formato flat-rate para aqueles que estivessem trabalhando e em benefícios não contributivos de natureza means-tested, voltados para aquelas pessoas que, por algum motivo, não estivessem no mercado de trabalho. Este modelo de políticas prevaleceu ao longo das décadas, tendo incorporado novos benefícios, como o auxílio desemprego e o auxílio doença no caso dos benefícios contributivos e o Child Benefit, em relação aos não contributivos. Apesar das mudanças ocorridas ao longo da Era Thatcher, como as verificadas nos índices de correção dos benefícios, maior regressividade no financiamento dos mesmos e estímulo à provisão privada de planos de aposentadoria, foi no governo do Novo Trabalhismo que se verificaram transformações substanciais na natureza dos benefícios, especialmente dos não contributivos. A condicionalidade imposta aos seus pleiteantes retirou o caráter assistencial de tais benefícios, deslocando-os para uma nova modalidade: aquela voltada para os working poor. Os créditos tributários passaram a atuar nesse campo, "empurrando" amplo contingente de pessoas vulneráveis para o mercado de trabalho. 
Em segundo lugar, demanda-se também ao setor privado algum esforço por meio de contratação em massa dos novos trabalhadores flexíveis. O governo, indiretamente, subsidiará esta mão de obra por meio da complementação dos ganhos laborais mediante concessão dos créditos tributários. A especificidade destes últimos refere-se ao fato de não serem computados, junto às Contas Nacionais, como gastos sociais - mas sim como redução na receita governamental - contribuindo ainda mais para o crescimento pouco expressivo dos gastos públicos (Glennester, 2007).

O Gráfico 2 também indica uma queda nos níveis de desigualdade social, acompanhada pela redução na pobreza relativa, especialmente a pobreza infantil, cujos altos índices prevalecentes na Era Thatcher colocaram seu combate no centro das políticas sociais do Novo Trabalhismo. A estratégia do governo visava promover a redução da exclusão social - o que implicava a queda nos níveis de desigualdade e pobreza - por meio da inserção dos indivíduos no mercado de trabalho, utilizando, para tanto, o sistema de créditos tributários, como complementação dos salários. Alguns destes benefícios tinham caráter cumulativo, como as Child Tax Credits, que eram concedidas às famílias comprovadamente pobres em conjunto com o Child Benefit, fortalecendo ainda mais a focalização no combate à pobreza infantil. Este é um importante fator explicativo da redução dos níveis de pobreza verificados ao longo do governo do Novo Trabalhismo e da elevação da mobilização para o trabalho. Nas palavras de Barr (2004): "Tax Credits to cover the costs of the child care have a particular importance. Because they offsets (holly or in part) one of the major costs of moving into work, they unambiguous improve both poverty relief and participation" (p. 224).

Proporção de alguns indicadores sociais e de gastos e benefícios sociais Reino Unido - 1995 e 2005

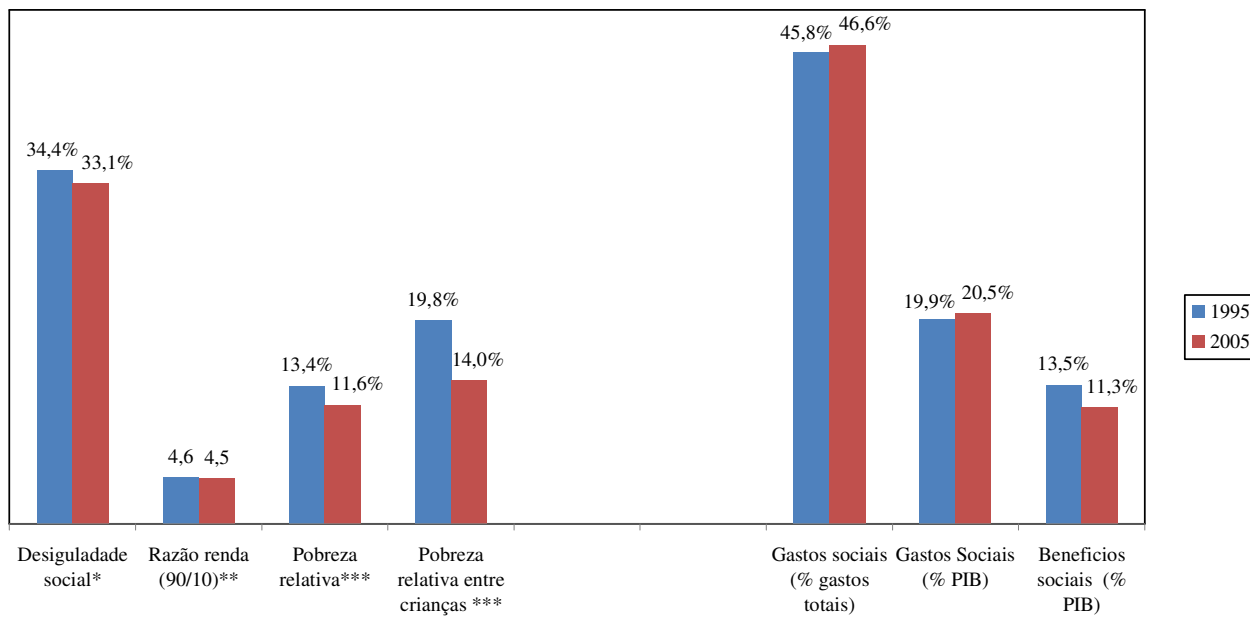

* Índice de Gini (em percentual); ** Razão entre a renda dos 10\% mais ricos e 10\% mais pobres; *** Percentual da população com renda abaixo de 50\% da renda mediana.

Fonte: Luxembourg Income Study; OECD (stat.extract); Institute of Fiscal Studies (IFS). 
O Gráfico 3 também mostra que, entre os períodos 1992/1997 e 1997/2005, houve uma melhora em todos os indicadores de mercado de trabalho, com uma queda significativa nas taxas de desemprego dos estratos populacionais analisados, assim como do desemprego de longo prazo. Estas informações sugerem ainda mais a articulação entre as políticas voltadas para a dinamização do mercado de trabalho e a estratégia de redução da desigualdade e pobreza no Reino Unido, ancoradas na participação, quase compulsória, dos indivíduos no mercado de trabalho.

Gráfico 3

Indicadores de Mercado de Trabalho

Reino Unido - 1992/2005

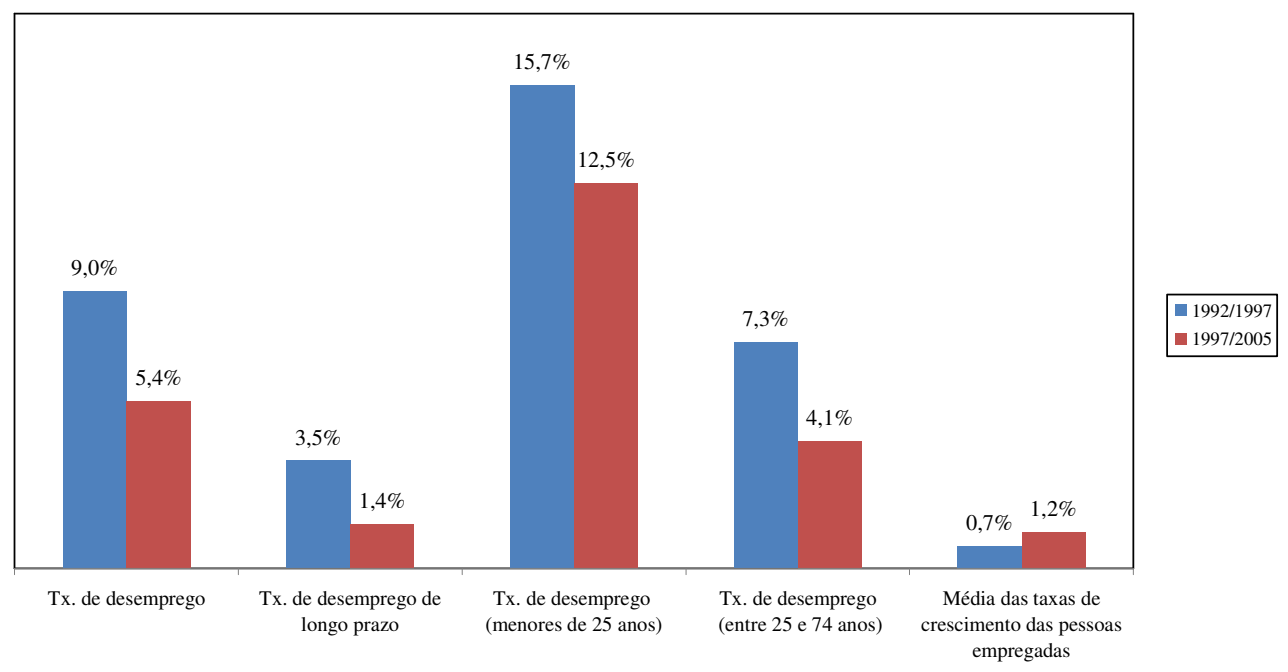

Fonte: Eurostat e Fundo Monetário Internacional (FMI).

Para apoiar este argumento, o Gráfico 4 mostra que houve crescimento significativo da taxa de participação no mercado de trabalho britânico entre 1991 e 2005, com maior intensidade entre as mulheres (54\%) quando comparado com os homens $(17,2 \%)$. Estas informações ganham maior relevância na comparação com o período 1981/1991, em que as referidas taxas sofreram variações tímidas, refletindo, muito provavelmente, os efeitos do processo de reestruturação econômica dos anos oitenta.

As melhorias nos indicadores sociais e de mercado de trabalho propiciadas pelo governo do Novo Trabalhismo ocorreram a partir de uma série de transformações produtivas e organizacionais, cujo maior impacto pôde ser notado nas mudanças na estrutura do mercado laboral. Sua flexibilização, no âmbito de uma economia cada vez mais associada ao setor de serviços, abriu caminho para o surgimento de uma série de novas ocupações, algumas vinculadas aos setores de ponta de tecnologia da informação (nicho de mercado no Reino Unido). Este mesmo 
movimento, por outro lado, também promoveu o crescimento de ocupações precárias, preenchidas principalmente pelos trabalhadores oriundos de um setor industrial cada vez mais fragilizado e em reestruturação. Nesse sentido, embora não exaustiva, torna-se importante uma análise mais aprofundada das características do mercado de trabalho britânico sob a gestão do Novo Trabalhismo, como forma de se compreender sob que condições as políticas sociais são reformatadas para apoiar o modelo de desenvolvimento britânico.

\section{Gráfico 4}

Taxa de participação da força de trabalho Britânica por Sexo - 1981/2005

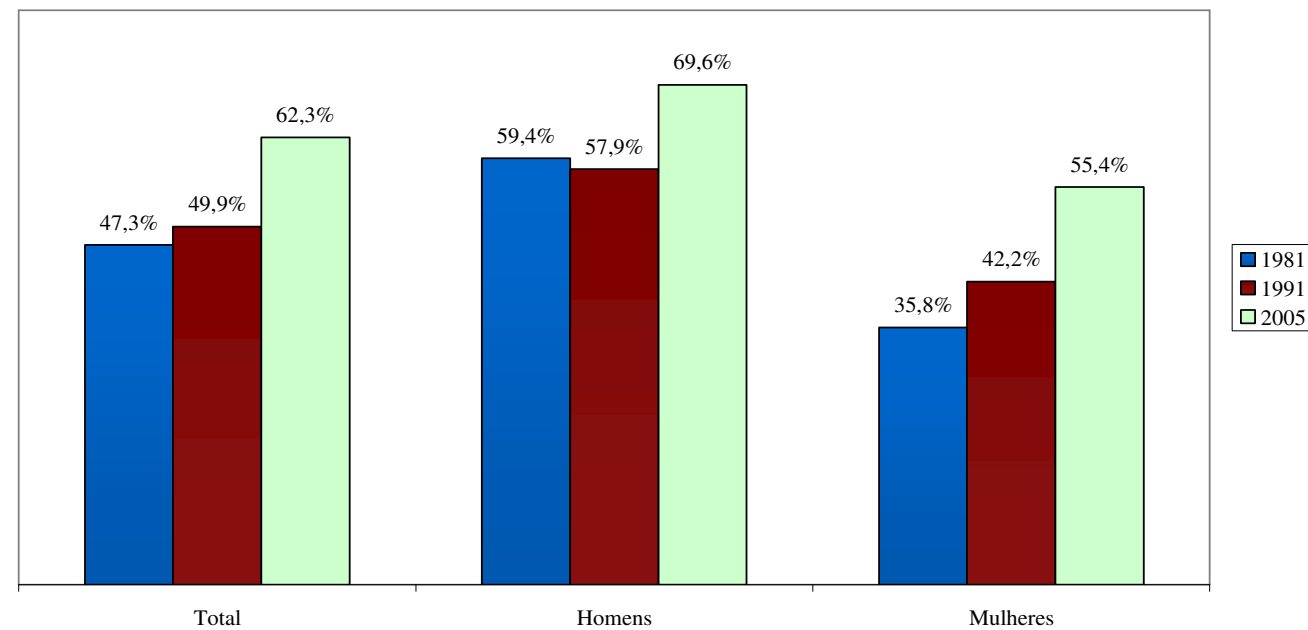

Fonte: OIT - Organização Internacional do Trabalho.

\subsection{Características do mercado de trabalho britânico no governo do Novo Trabalhismo}

O governo da Primeira Ministra Margareth Thatcher promoveu uma profunda e extensa reestruturação da economia britânica, a partir de um conjunto de medidas que visaram a desregulamentação tanto do mercado financeiro quanto do mercado de trabalho. Esta estratégia, utilizada como alternativa para a saída da crise dos anos 70, promoveu impactos significativos sobre a estrutura do emprego no Reino Unido.

O primeiro impacto se reflete na queda no emprego industrial, vinculado, por sua vez, à ausência de políticas voltadas para a reestruturação de longo prazo do setor (Tabela 2). Relacionado a este processo está o enfraquecimento do poder de influência dos sindicatos, o que tornou os salários mais flexíveis e determinados basicamente pelas condições de oferta e demanda do mercado. 
O segundo destes impactos se refere à expansão do emprego no setor de serviços, o que refletiu a estratégia do governo de ancorar a dinâmica da economia em uma base pós-industrial. Como mostram as informações da Tabela 2, o emprego no terciário já era predominante no início dos anos 80, sendo sua principal característica o fato de abranger uma proporção significativa de mulheres. $\mathrm{O}$ crescimento das ocupações vinculadas ao setor de serviços ao longo desta década e das posteriores permitiu a absorção dos trabalhadores oriundos do setor industrial cada vez mais decadente, fato este que se reflete na igual absorção da força de trabalho masculina no setor de serviços.

Para qualificar melhor esta informação, o Gráfico 4 mostra que o aumento do emprego no setor de serviços impulsionou a oferta de empregos de meio período ou temporários, também chamados de part-time employment ${ }^{12}$. Este tipo de emprego apresenta características distintas do emprego industrial, pois não é necessariamente regulado pela relação salarial estabelecida entre patrões e empregados, estando, por outro lado, vinculado às características de um mercado de trabalho desregulamentado. Em grande medida, os empregos de tipo part-time podem ser considerados "empregos precários", já que são basicamente de baixa qualificação, além de contarem com salários abaixo da média do mercado. Entre 1984 e 2005, a participação deste tipo de emprego no total do emprego no Reino Unido passou de $19,4 \%$ para $23 \%$. Este crescimento foi ainda mais expressivo no caso dos jovens entre 15 e 24 anos, em que o emprego part-time passou de 12,7\% em 1984 para $32,7 \%$ em 2005 .

Tabela 2

Distribuição Proporcional* do Emprego no Reino Unido por Sexo segundo Setores de Atividades - 1980/2005

\begin{tabular}{l|c|c|c}
\hline \multicolumn{1}{c}{$\begin{array}{c}\text { Setores de } \\
\text { Atividades }\end{array}$} & 1980 & 1997 & 2005 \\
\cline { 2 - 4 } & \multicolumn{3}{c}{$\%$} \\
\hline Agricultura & 2,6 & 1,8 & 1,3 \\
Masculino & 3,4 & 2,5 & 1,9 \\
Feminino & 1,3 & 1,0 & 0,8 \\
Indústria & 37,7 & 26,7 & 22,2 \\
Masculino & 46,9 & 37,8 & 33 \\
Feminino & 22,6 & 13,1 & 9,5 \\
Serviços & 58,9 & 71,1 & 76,3 \\
Masculino & 47,7 & 59,3 & 64,9 \\
Feminino & 76,0 & 85,6 & 89,6 \\
\hline
\end{tabular}

* A soma nem sempre é $100 \%$ em virtude de algumas ocupações não terem sido adequadamente definidas em nenhum dos setores de atividades

Fonte: OIT - KILM.

(12) A definição usual de part-time employment se refere àquele trabalho que consumiu menos de 30 horas semanais dos trabalhadores, seja em ocupações formais ou informais (OCDE, 2012). 
O Gráfico 4 mostra ainda que as mulheres britânicas preencheram mais de $60 \%$ das ocupações de características part-time em todos os períodos e faixas etárias analisadas, o que mostra ser este importante fator explicativo da participação feminina no mercado de trabalho (Lavinas, 2011). Esta predominância, no entanto, se reduziu ao longo do tempo, em virtude do aumento da participação masculina neste tipo de emprego ${ }^{13}$. Dessa forma, em 1984, as mulheres com mais de 25 anos ocupavam $91 \%$ dos empregos part-time britânicos, percentual que caiu para $82 \% \mathrm{em}$ 2005. As mulheres com idade entre 15 e 24 anos, por sua vez, ocupam uma proporção de vagas inferior aos demais estratos, o que indica que entre os jovens, os homens apresentam uma participação mais robusta nas ocupações de meio período.

A análise destas informações permite que se façam dois comentários a respeito da estratégia de desenvolvimento do governo do Novo Trabalhismo:

Em primeiro lugar, as políticas de estímulo ao crescimento do emprego foram implementadas sem romper com a estrutura do mercado de trabalho britânico herdada da Era Thatcher, ou seja, manteve-se a tendência de queda do emprego industrial e crescimento das ocupações do setor de serviços, com elevações de atividades precárias e part-time. Manteve-se dessa forma, a estratégia de se criar um sistema econômico de base Pós-Industrial, o que pode ser visto no crescimento de mais de 7\% no emprego no setor de serviços entre 1997 e 2005, ao mesmo tempo em que se registrou uma queda de quase $17 \%$ no emprego industrial (Tabela 1).

Em segundo lugar, a gestão Blair/Brown não reduziu a proporção dos empregos de tempo parcial (Gráfico 4). Os mesmos se mantiveram estáveis, tanto no total, quanto na população com mais de 25 anos. No caso da população com idade entre 15 e 24 anos, no entanto, houve um incremento de aproximadamente $10 \%$ neste tipo emprego, em que os mesmos passaram de 29,6\% em 1997 para 32,7\% em 2005.

O crescimento do emprego precário entre os jovens possui importância significativa para as políticas do Novo Trabalhismo, em especial aquelas voltadas para o aumento da empregabilidade deste estrato populacional. Como observado anteriormente, o estímulo ao crescimento do emprego na população entre 18 e 24 anos foi a primeira iniciativa tomada pelo governo Tony Blair no âmbito do New Deal do Novo Trabalhismo. De fato, pelo Gráfico 3, nota-se que houve redução no desemprego da população com menos de 25 anos, o que mostraria a efetividade destas medidas. Entretanto, ao se tomar o crescimento e a participação do emprego

(13) O enfraquecimento dos sindicatos ao longo dos anos 80 , em conjunto com a redução da atividade industrial, deslocou a força de trabalho do setor manufatureiro para as atividades de serviços, vinculando-a a um mercado de trabalho flexibilizado. Isto significou a perda da estabilidade nos ganhos salariais que até então era garantida aos empregados do setor industrial, pois se rompeu a relação salarial que garantia o poder de barganha dos trabalhadores juntos aos empresários. Em outras palavras, a migração dos trabalhadores da indústria para as ocupações temporárias e de meio período ocorreu no âmbito do aumento da precarização do mercado de trabalho, já que estas ocupações não necessariamente garantiam condições mínimas de subsistência ao trabalhador. 
temporário na população entre 15 e 24 anos como uma proxy do crescimento do emprego entre os jovens de 18 a 24 anos, infere-se que o aumento dos empregos part-time contribuiu para a redução das taxas de desemprego entre os jovens britânicos.

\section{Gráfico 5}

Participação do emprego part-time no emprego total e proporção das mulheres no emprego part-time por faixa etária

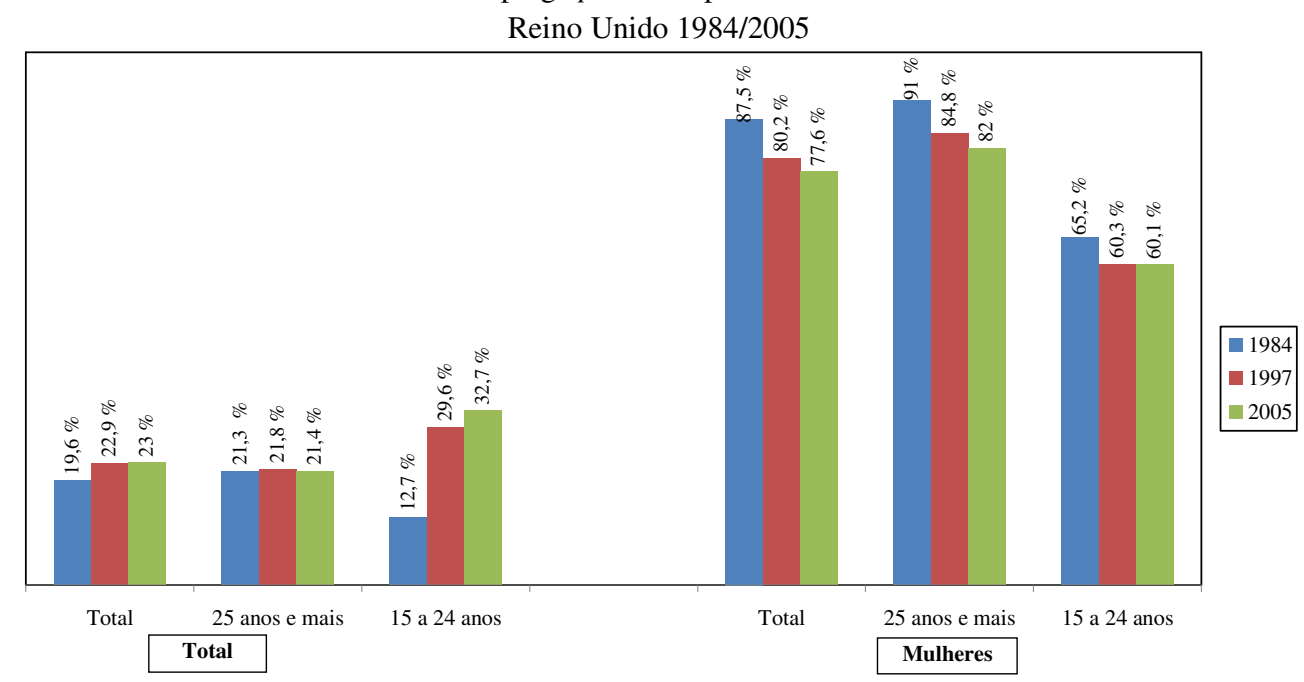

Fonte: OIT - KILM.

Em outras palavras, as políticas voltadas para a dinamização do mercado de trabalho não lograram romper com a institucionalidade criada ao longo do processo de desregulamentação e flexibilização dos mercados iniciados na Era Thatcher. A manutenção de uma estrutura a qual os empregos precários mantêm relevante participação na composição do emprego total - quando comparado com outros países $^{14}$-, mostra sua importância nas políticas voltadas para a incorporação dos grupos sociais à margem do mercado laboral.

Esta constatação ajuda a compreender a natureza das políticas de transferência de renda, que passaram a estar fortemente ancoradas na concessão de créditos tributários para as pessoas que estivessem trabalhando ou procurando emprego. Em primeiro lugar, um número significativo de indivíduos vulneráveis e reticentes ao trabalho precário passa a ser absorvido por imposição da política de

(14) A Organização Internacional do Trabalho (OIT, 2012) fornece as seguintes informações sobre a participação do emprego part-time, no emprego total, para o grupo de quatro países em 2005: Alemanha (21,5\%); França (13,2\%); Noruega (20,8\%); Suécia (13,5\%). A alta proporção observada para a Alemanha em 2005 contrasta com os $15,8 \%$ verificado em 1997 , indício de que seu mercado de trabalho vem passando por transformações significativas. 
proteção social. Aceitam-se baixas remunerações, pois elas são o colateral exigido pelo Estado para assegurar um nível pouco melhor de bem-estar. Forma-se aí um paradoxo, em que os trabalhadores, para não viverem precariamente, passam a aceitar um emprego precário.

Em segundo lugar, a absorção em empregos de meio período, de parte da população antes desempregada, contribuiu para o crescimento da oferta de trabalho de baixa qualificação - especialmente para os jovens. Dessa forma, haveria mais trabalhadores disputando espaço no mercado de trabalho, o que culminaria com a redução dos salários e, portanto, dos custos de produção. Esta era a meta estabelecida pelo governo no âmbito das políticas de mercado de trabalho.

Estas constatações permitem localizar com mais precisão o lugar ocupado pelas políticas sociais - por meio das políticas de transferência de renda - na estratégia de desenvolvimento britânica. Sua importância está associada às políticas de dinamização do mercado de trabalho, mas restritas, ao mesmo tempo, a uma estrutura laboral segmentada e composta por um elevado contingente de trabalhadores precários e destituídos de status. Esta última característica justifica o formato destas políticas, ou seja, a concessão de créditos tributários para quem estivesse no mercado de trabalho complementaria os baixos rendimentos gerados pelos empregos precários.

\section{Conclusões}

As novas ideias que passaram a pautar a condução das políticas dos governos Blair/Brown atribuíam ao Estado importância central no processo de reestruturação do sistema econômico. Nesse sentido, destaca-se a defesa da parceria entre Estado e mercado para garantir que os frutos da globalização sejam canalizados para o bemestar social da população britânica. Este processo fundamentou uma estratégia de desenvolvimento que restabeleceu os vínculos entre o mercado e as instituições políticas e sociais britânicas. O Estado, dessa forma, não era mais encarado como prejudicial à eficiência do mercado, tendo a função de potencializar e generalizar a expansão das relações mercantis para a sociedade.

A partir de um novo discurso que relacionava o acesso aos direitos sociais como consequência do cumprimento de obrigações - relacionadas à participação dos indivíduos no mercado de trabalho - o governo justificou a elaboração de uma série de políticas voltadas para a inclusão no mercado laboral de grupos sociais mais vulneráveis. O trabalho, para o Novo Trabalhismo, traria autonomia para esses indivíduos, livrando-os da dependência dos benefícios estatais e tornando-os parte integrante do projeto de desenvolvimento da nação.

A natureza destas políticas, entretanto, mais do que incentivar, forçou a entrada desses indivíduos no mercado de trabalho, sob o risco de perderem o direito 
a benefícios assistenciais. Para recebê-los era necessário comprovar um mínimo de horas trabalhadas. $\mathrm{O}$ workfare foi institucionalizado. $\mathrm{O}$ argumento principal era de que o aumento da oferta de trabalho reduziria os custos de produção dos empresários, já que haveria concorrência entre os trabalhadores pelos empregos. Como resultado, a produção cresceria. Além disso, garantir-se-ia aos trabalhadores o acesso aos direitos sociais, assim como a autonomia conquistada pela entrada no mercado laboral.

O Estado, desta forma, viabilizou a articulação entre as políticas econômicas e sociais ao criar um sistema de benefícios que contemplava aqueles indivíduos com necessidades, porém que estivessem no mercado de trabalho, em detrimento de quem estivesse fora. Ao direcionar estes grupos mais vulneráveis para o mercado laboral, por sua vez, o Estado restringiu os gastos com benefícios, substituindo-os pela concessão de créditos tributários, como forma de complementação dos salários recebidos no mercado. Como resultado desta parceria Estado/mercado houve o aumento da oferta de trabalho na economia, em conjunto com a redução dos gastos públicos com benefícios sociais.

Ocorre que este processo não rompeu com as características do mercado de trabalho britânico, cuja reestruturação ao longo da Era Thatcher elevou significativamente a proporção de empregos precários. O novo modo de regulação que se formou a partir da articulação entre políticas sociais e econômicas reproduziu esta estrutura, ou seja, empregos foram criados nos setores mais dinâmicos da economia - como os associados às atividades da tecnologia da informação. Ao mesmo tempo, se manteve proporção elevada de empregos precários, que atingiu principalmente os jovens.

Dessa forma, a parceria Estado/mercado, firmada pelo governo do Novo Trabalhismo, mostrou seus limites quando se tentou inserir este último em uma ordem social marcadamente segmentada. A institucionalização do workfare regime forneceu suporte ao crescimento de uma economia pós-industrial, cujo mercado de trabalho flexibilizado absorveu, em empregos precários, significativa parcela dos grupos populacionais vulneráveis no Reino Unido.

\section{Referências bibliográficas}

AGHION, P.; DURLAUF, S. From growth theory to policy design. Apr. 3, 2007. p. 1-28. Disponível em: <http://www.growthcommission.org/storage/cgdev/documents/aghiondurlauf-wbapr3fin.pdf $>$. Acesso em: 6 maio 2012.

BARR, N. The economics of the welfare state. $4^{\text {th }}$. ed. Oxford: Oxford University Press, 2004. 407p. 
BLANK, R. Evaluating welfare reforms in the United States. May, 2002, 125p. Disponível em: http://www.fordschool.umich.edu/research/papers/PDFfiles/02-003.pdf. Acesso em: 8 nov. 2013.

DEPARTMENT OF EDUCATION AND EMPLOYMENT. A new contract for welfare: The Gateway to Work. London: The Stationery Office, Oct. 1998, 13p. Disponível em <http://www.politiquessociales.net/IMG/pdf/gateway.pdf>. Acesso em: 6 maio 2012.

FAUCHER-KING, F.; LE GALÈS, P. The new labour experiment: change and reform under Blair and Brown. Stanford: Stanford University Press, 2010. 183p.

FRASER, D. The evolution of the British Welfare State. New York: Palgrave Macmillan, 2009. 434p.

GIDDENS, A. A terceira via: reflexões sobre o impasse político atual e o futuro da socialdemocracia. Rio de Janeiro: Record, 1999. 173p.

GLENNESTER, H. British Social Policy: 1945 to the present. Oxford: Blackwell Publishing, 2007. p. 321.

GLYN, A.; WOOD, S. Economic policy under new labour: how social democratic is the Blair government? The Political Quarterly, v. 72, n. 1, p. 50-66, 2001.

JESSOP, B. From Thatcherism to new labour: neo-Liberalism, workfarism, and labour market regulation. In: THE POLITICAL economy of European employment: European integration and the transnationalization of the (un)employment question. London: Routledge, 2003. p. 137-153.

HALL, P. A. Policy paradigms, social learning and the state: the case of economic policymaking in Britain. In: INSTITUTO Juan March de Estudios e Investigaciones, Centro de Estudios Avanzados en Ciencias Sociales, Madrid, 1990, p. 30.

HOLDEN, C. Decommodification and the Workfare State. Political Studies Review, v. 1, p. 303-316, 2003.

LE GRAND, J. Quasi-markets and social policy. The Economic Journal, v. 101, n. 408, p. 1256-1267, Sept. 1991.

LAVINAS, L. Estratégias femininas para considerar trabalho remunerado e trabalho doméstico no século XXI. Revista da ABET, v. 10, n. 2, jul./dez. 2011.

LUCAS, R. E. On the mechanics of economic development. Journal of Monetary Economics, n. 22, p. 3-42, 1988.

LUND, B. Major, Blair and the third way. Social Policy \& Administration, v. 42, n. 1, p. 43-58, Feb. 2008.

NELSON, R. R.; SAMPAT, B. N. Making sense of institutions as a factor shaping economic performance. Journal of Economic Behavior \& Organization, v. 44, n. 1, p. 31-54, 2001. 
NORTH, D.C. Institutions, institutional change, and economic performance. Cambridge: Cambridge University Press, 1990. 153p.

PLANT, R. Citizenship and social security. Fiscal Studies, v. 24, n. 2, p. 153-166, 2003.

ROMER, P. Increasing returns and long-run growth. The Journal of Political Economy, v. 94, n. 5, p. 1002-1037, Oct. 1986.

SOLOW, R. M. A contribution to the theory of economic growth. The Quarterly Journal of Economics, v. 70, n. 1, p. 65-94, Feb. 1956.

SWAN, T. Economic growth and capital accumulation. Economic Record, 32, n. 2, p. 334361, 1956.

TAVARES, M. C. Ajuste e reestruturação nos países centrais: a modernização conservadora. In: TAVARES, M. C.; FIORI, J. L. (Des)ajuste global e modernização conservadora. Rio de Janeiro: Paz e Terra, 1993. p. 21-73. 